\title{
Pattern of Respiratory Diseases among Admitted Children in Pediatric Pulmonology Unit : A Tertiary Center Experiences
}

1 Dr. Jotsna Ara Begum Associate Professor (Ex) Dept. of Pediatric Respiratory Medicine (Pulmonology) Bangladesh Institute of Child Health (BICH)

Dhaka Shishu (Children) Hospital

2 Dr. Mohammad Abdullah AI Mamun Assistant Professor

${ }^{3}$ Dr. Akhand Tanzih Sultana Assistant Professor

${ }^{4}$ Dr. Md. Kamruzzaman Registrar

${ }^{5}$ Dr. AFM Ashik Imran Osteopathic Medical Student NYITCOM, USA

${ }^{6}$ Dr. Mst. Laizuman Nahar MPH Student, SUNY, USA

\section{$2,3,4$}

Dept.of Pediatric Respiratory Medicine (Pulmonology) BICH, Dhaka Shishu (Children) Hospital

\section{Correspondence}

Dr. Jotsna Ara Begum

Ex-Associate Professor

Dept. of Pediatric Respiratory

Medicine (Pulmonology)

Bangladesh Institute of Child Health, Dhaka Shishu (Children) Hospital e-mail: jotsna_ajn@yahoo.com

\section{J A Begum ${ }^{1}$, M A A Mamun², A T Sultana ${ }^{3}$, M Kamruzzaman ${ }^{4}$, A F M A Imran ${ }^{5}$, M L Nahar ${ }^{6}$}

Abstract

Background : The spectrum of respiratory illness is wide and includes diseases of upper and lower airways, communicable and non-communicable types. The variation in pattern of morbidity mortality of respiratory illness may be affected by different environmental and climatic variation in different parts of the world.

Objective : The present study intended to explore the pattern of respiratory illnesses seen in Bangladeshi children admitted with respiratory illnesses.

Methods : The present prospective observational study was conducted in children up to 12 years of age admitted with acute respiratory illness in pulmonology unit of Dhaka Shishu (Children) Hospitalfrom July 2012 to July 2013. All children between the age limit with acute respiratory illness were included in the study. A standardized questionnaire was formulated and pretested. Then the data were collected through interview by using the questionnaire. Data were analyzed using SPSS version 17.

Results : Total 1169 patients were admitted under pulmonology unit during July 2012 to June 2013 among them $324(27.7 \%)$ were admitted with respiratory diseases. Among the respiratory diseases Pneumonia (71.2\%), Acute Bronchiolitis (20.1\%), Bronchial Asthma $(4.2 \%)$ and TB $(2.7 \%)$ were commonest. Bronchopneumonia, Acute Bronchiolitis, Bronchial Asthma and TB was common among under 5 children and less common after 5 years. Male were predominate in every cases. Majority of respiratory cases were belonged to poor socioeconomic status. Pneumonia $(50.7 \%)$ and Acute Bronchiolitis (58.5\%) cases were found during autumn and late autumn. Asthma was common during late autumn and winter and Tuberculosis was common throughout the year. Mortality was higher among pneumonia cases.

Conclusions : Respiratory illness contributes most common cause of admission in tertiary care pediatric hospital. Bronchopneumonia is still the commonest respiratory disease with leading cause of mortality.

Key words : Respiratory illness, pulmonology unit, tertiary center

DOI: http://dx.doi.org/10.3329/nimcj.v9i2.38913

Northern International Medical College Journal Vol. 9 No. 2 January 2018, Page 308-310

\section{Introduction}

Respiratory illness is the important indication for admission in pediatric hospitals. ${ }^{1}$ In children respiratory illness form a substantial disease burden in emergency care, outpatients and hospitalized patients. Respiratory symptoms comprise $27.5 \%$ of pediatric emergency department visits. ${ }^{2}$ It remain a major cause of morbidity and mortality in children., ${ }^{3,4}$ In the developing world, respiratory tract infections along with diarrheal diseases constitute the major causes childhood morbidity and mortality particularly in under five age group. ${ }^{5}$ Globally, a systematic review found Pneumonia, a respiratory illness, as the leading cause of morbidity and mortality in children aged below 5 years. $^{6}$

The spectrum of respiratory illness is wide and includes diseases of upper and lower airways, communicable and non-communicable types. The variation in pattern of morbidity mortality of respiratory illness may be affected by different environmental and climatic variation in different parts of the world. ${ }^{7}$ Apart from pneumonia, children may suffer a variety of respiratory illness ranging from common cold, Nasopharyngitis, Laryngitis, Sinusitis, Bronchiolitis, Tonsillopharyngitis, Asthma, Tuberculosis, Foreign body Aspiration etc. Some of these cases may require hospital admission based on its severity. The spectrum of illness in a given locality may differ from another. 
In Bangladesh, Acute Respiratory Tract Infections (ARI) alone is responsive $38.8 \%$ of total Paediatric hospital admission and among the 1,82,936 under-five childhood deaths in Bangladesh, $14 \%$ were due to pneumonia. 8,9 The two most common causes of ARI in children below 2 years of age are bronchiolitis and community acquired pneumonia (CAP). ${ }^{10}$ Prevalence of childhood asthma is substantial and asthma has often been treated as pneumonia and under-diagnosed in developing countries. ${ }^{11}$ Bangladesh is no longer any exception of them with low prevalence. ${ }^{12}$

Nevertheless, much of the data is extrapolated from geographical regions elsewhere with different demographics and there is paucity of epidemiological data on children admitted with respiratory complaints in the context of Bangladesh. The present study intended to explore the pattern of respiratory illnesses seen in Bangladeshi children admitted with respiratory illnesses inpediatricpulmonology unit of Dhaka Shishu (Children) Hospital which is largest pediatric hospital in Bangladesh.

\section{Materials and Methods}

This prospective observational study was conducted in children up to 12 years of age admitted with acute respiratory illness at pulmonology unit of Dhaka Shishu (Children) Hospital from July 2012 to July 2013 after taking permission from institutional ethical committee. All children between the age limit with acute respiratory illness were included in the study. Children suffering from coexisting diseases like congenital heart disease, immunodeficiency and children admitted outside of the specified time period and children whose parents not willing to give consent were excluded from the study. A standardized questionnaire was formulated and pretested, and then questionnaire was filled up through interviewing during data collection. Finally, data were analyzed by using SPSS version 17.

\section{Results}

Total1169 patients were admitted under pulmonology unit during July 2012 to July 2013 among them 324(27.7\%) were admitted with respiratory diseases (Fig.-1).

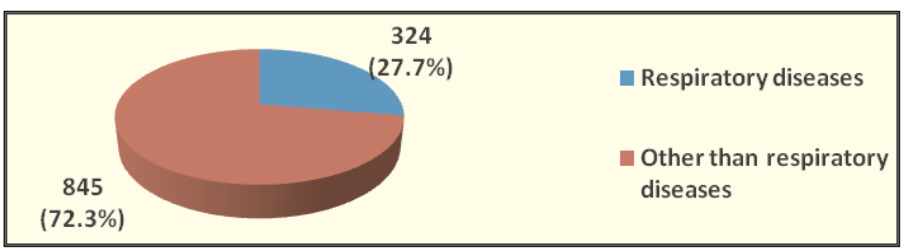

Fig.-1: Distribution of admitted patients under pulmonology unit $(n=1169)$

Among the respiratory diseases pneumonia (71.2\%), acute bronchiolitis (20.1\%), bronchial asthma (4.2\%) and TB (2.7\%) were commonest (Table-I).
Table-I : Distribution of respiratory diseases $(n=324)$

$\begin{array}{lcc}\text { Respiratory disease } & \text { Number } & \text { Percent } \\ \text { Abscess (lung) } & 1 & 0.3 \\ \text { Acute Bronchiolitis } & 65 & 20.1 \\ \text { Asthma } & 14 & 4.2 \\ \text { Laryngomalacia } & 3 & 0.9 \\ \text { Pneumonia } & 231 & 71.2 \\ \text { TB } & 6 & 1.7 \\ \text { URTI (Upper Respiratory Tract Infection) } & 1 & 0.3 \\ \text { Wheezy Child } & 1 & 0.3 \\ \text { Total } & 324 & 100\end{array}$

Pneumonia was common among under 5 children and a large number of Pneumonia occurred during neonatal period (30. 3\%).Bronchiolitis, Asthma and TB was also common among under 5 children and less common after 5 years. Male were predominating in every cases. Majority of respiratory cases were belonged to poor socioeconomic status (Table-II).

Table-II: Baseline characteristics of study population with respiratory diseases $(n=324)$

\begin{tabular}{|c|c|c|c|c|c|}
\hline $\begin{array}{l}\text { Baseline } \\
\text { characteristics }\end{array}$ & & $\begin{array}{l}\text { Bronchopneumonia } \\
\qquad(n=231)\end{array}$ & $\begin{array}{l}\text { Acute bronchiolitis } \\
\qquad(n=65)\end{array}$ & $\begin{array}{l}\text { Asthma } \\
(n=14)\end{array}$ & $\begin{array}{c}\text { TB } \\
(n=6)\end{array}$ \\
\hline \multirow[t]{3}{*}{ Age } & $0-28 d$ & $70(30.3)$ & - & - & - \\
\hline & $1 m-5 y$ & $126(54.5)$ & $65(100)$ & $12(85.7)$ & $5(83.3)$ \\
\hline & $>5 y$ & $35(15.2)$ & - & $2(14.3)$ & $1(16.7)$ \\
\hline \multirow[t]{2}{*}{ Sex } & Male & $155(67.1)$ & $44(67.7)$ & $9(64.3)$ & $3(50)$ \\
\hline & Female & $76(32.9)$ & $21(32.3)$ & $5(35.7)$ & $3(50)$ \\
\hline \multirow[t]{2}{*}{ Residence } & Urban & $105(45.6)$ & $35(53.8)$ & $7(50)$ & $4(66.7)$ \\
\hline & Rural & $126(54.4)$ & $30(46.2)$ & $7(50)$ & $2(33.3)$ \\
\hline \multirow[t]{3}{*}{ Socioeconomic status } & Poor & $125(54.1)$ & $41(63.1)$ & $8(57.1)$ & $4(66.6)$ \\
\hline & Middle & $82(35.5)$ & $19(29.2)$ & $6(42.9)$ & $1(16.7)$ \\
\hline & High & $24(10.4)$ & $5(7.7)$ & - & $1(16.7)$ \\
\hline
\end{tabular}

Majority of Pneumonia cases were found during Autumn and late Autumn (50.7\%). Similarly highest Bronchiolitis cases were found during Autumn and late Autumn (58.5\%) and less common during Spring and Summer. Asthma was common during late autumn and winter (64.3\%). Tuberculosis was common throughout the year (Fig.-2).

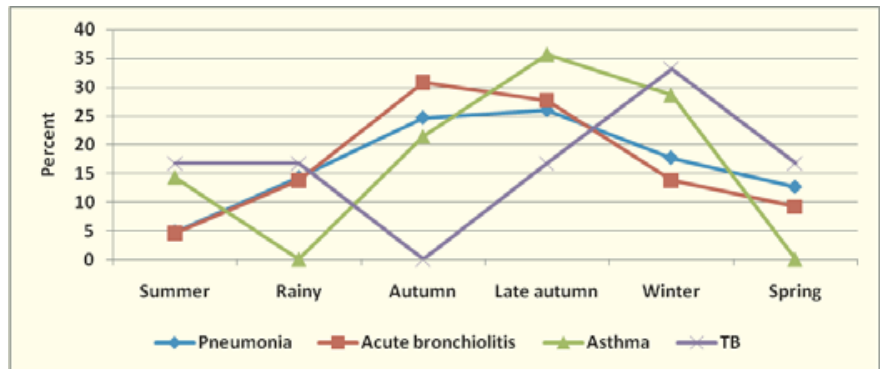

Fig.-2 : Seasonal variation of respiratory illness among study population $(n=324)$ 
Majority of Pneumonia patients (83.1\%)were discharged with advised (DA), (7.8\%)got discharge on risk bond (DORB), $4.8 \%$ discharged on request (DOR) and $3.9 \%$ cases died. Among Acute Bronchiolitis cases DA was $90.8 \%$, DOR and DORB were $4.6 \%$ and $3.1 \%$ respectively Mortality of Acute Bronchiolitis was $1.5 \%$. Among Asthma patients $85.7 \%$ got DA and $14.3 \%$ were discharged on request. Among TB patients $83.3 \%$ got DA and $16.7 \%$ got DORB (Table-III).

$\begin{array}{lcccc}\text { Table-III } & \text { : Outcome of respiratory diseases }(\mathbf{n}=324) & & \\ \text { Outcome } & \text { Bronchopneumonia } & \text { Acute bronchiolitis } & \text { Asthma } & \text { TB } \\ \text { DA } & 192(83.1) & 59(90.8) & 12(85.7) & 5(83.3) \\ \text { DOR } & 11(4.8) & 3(4.6) & 2(14.3) & - \\ \text { DORB } & 18(7.8) & 2(3.1) & - & 1(16.7) \\ \text { Referred } & 1(0.4) & - & - & - \\ \text { Death } & 9(3.9) & 1(1.5) & - & - \\ \text { Total } & 231(100) & 65(100) & 14(100) & 6(100)\end{array}$

\section{Discussion}

Respiratory illness is the important indication for admission intertiary care Paediatric hospital. In this study total admission on respiratory illness was $27.7 \%$. Akbar et al. found respiratory tract infections alone is responsive $38.8 \%$ of total pediatric hospital admission. ${ }^{8}$ In a study of admissions in hospitals in Hong Kong respiratory disorders constituted $37.5 \%$ of all diagnosis. $^{13}$

The cause of high incidence of respiratory illness in this study was because of early referral to tertiary care hospital as Dhaka Shishu (Children) Hospital is the largest tertiary care hospital of Bangladesh.

Among the respiratory diseases Bronchopneumonia (71.2\%), Acute Bronchiolitis (20.1\%), Bronchial Asthma (4.2\%) and TB $(2.7 \%)$ were commonest respiratory illness. Nagarajet al. in India found Acute Bronchiolitis (33\%) followed by Broncho pneumonia (25.3\%) and Asthma (16.3\%). ${ }^{1}$ Das Set al. found similar result in his study. ${ }^{14}$ In developing countries Bronchiolitis and Bronchopneumonia are the major contributing respiratory illness. Overcrowding, poor sanitation, poverty are main risk factors for Bronchopneumonia.

Bronchopneumonia was common among under 5 children and a large number of Pneumonia occurred during neonatal period. Nagarajet al. found highest number ofpatients of respiratory illness belonged to less than 6 month age group. ${ }^{1}$ The cause was unknown, it might be decreased practice of breast feeding the major predisposing factor for respiratory illness.

Majority of the respiratory cases were belonged to poor socio economic status. In this study more number of cases were admitted during autumn, late autumn and winter. Nagarajet al.in India found more number of respiratory cases during November (23.6\%) and December (26.6\%) which is the beginning of winter of that area. ${ }^{1}$ Earlier study done in Nigeria recorded similar peak period in November. ${ }^{5}$ The drastic change in temperature and cold weather are the contributing factors for seasonal variation of respiratory illness. According to various studies respiratory illness are the most common cause of morbidity and mortality in under five children. In this current study mortality was higher in Pneumonia. $8,9,12$

\section{Conclusion}

Respiratory illness contributes most common cause of admission in tertiary care pediatric hospital. Bronchopneumonia is still the commonest respiratory disease with leading cause of mortality.

\section{References}

1. Nagaraj N, Subramanian R, Berwal PK, Agrawal R, Solaria S, Saini TC. A study of prevalence and frequency of respiratory illness in hospitalized children in North West part of Rajasthan. Indian Journal of Immunology and Respiratory Medicine, January-March 2016;1;5-8.

2. Das S, Ray SK, Mukherjee M, AnirbanMaitra A, Chatterjee K, Sen S. Epidemiology of admissions with respiratory illnesses: a single tertiary centre experience. Int J ContempPediatr. 2017;4:378-82.

3. Akanbi MO, Ukoli CO, Erhabor GE, Akanbi FO, Gordon SB: The burden of respiratory disease in Nigeria. Afri J Resp Med 2009,4:10-17.

4. Rudan I, Boschi-pinto C, Biloglav Z, Mulholland K, Campbell H: Epidemiology and etiology of childhood pneumonia. Bull World Health Organ 2008,86:408-416.

5. Akanbi MO, Ukoli CO, Erhabor GE, Akanbi FO, Gordon SB: The burden of respiratory disease in Nigeria. Afri J Resp Med 2009,4:7-10.

6. Lozano R, Naghavi M, foreman K, Lim S, Shibuya K, aboyans V, et al. Global and regional mortality from 235 causes of death for 20 age groups in 1990 and 2010: A systemic analysis for the global burden of Disease study 2010. Lancet. 2012;380:2095-2128.

7. Otters HB, van der Wouden JC, Schellevis FG, van Suijlekom-Smit LW, Koes BW: Changing morbidity patterns in chidren in Dutch general practice: 19872001. Eur J Gen Pract 2005:11:17-22.

8. Akbar, MS, Ehsan A, Ali CMH. Clinical profile \& management of acute Resp tract infection at Dhaka Shishu Hospital, Bangladesh J Child Health1992;16, 5-8.

9. Black RE, Cousen $\mathrm{S}$, Johnson $H \mathrm{~L}$, Lawn JE, Rudan I, Bassani DG, et al. Global, regional, and national causes of child mortality in 2008: a systematic analysis. Lancet 2010;375, 1969-87.

10. Haque F, Husain MM, Ameen KM, Rahima R, Hossain MJ, Alamgir AS, et al. Bronchiolitis outbreak caused by respiratory syncytial virus in southwest Bangladesh, 2010. Int J Infect Dis 2012;16: e866-71.

11. Nantranda R, TumwinJK.,Ndeezi G, Ostergaard M S. Asthma and Pneumonia among Children Less Than Five Years with Acute RespiratorySymptoms in Mulago Hospital, Uganda: Evidence of Under-Diagnosis of Asthma. PLoS One, 8, e81562.

12. Kabir ML, Rahman F, Hassan MQ, Ahmed F, Mridha MA. (2005) Asthma, atopic eczema and allergicrhino-conjunctivitis in school children. Mymensingh Med J 2005; 14: 41-5.

13. Nelson EAS, Tam JS, Yu LM, Li AM, Chan PKS, Sung RYT: assessing disease burden of respiratory disorders in Hong Kong children with Hospital discharge data and linked laboratory data. Hong Kong Med J 2007,13:114-121.

14. Das $\mathrm{S}$ et al Epidemiology of admissions with respiratory illnesses: a single tertiary centre experience. Int J ContempPediatr. 2017 Mar;4(2):378-382 